\title{
A study investigating the effects of Mindfulness-Based Strengths Practice (MBSP) on wellbeing
}

\author{
Itai Ivtzan • Ryan M. Niemiec · Charlie Briscoe
}

\begin{abstract}
Mindfulness practice and character strengths have been determined as being two separate positive psychology interventions (PPIs). However, to date, no programme has researched and investigated the effects of combining these theoretically interlinked practices together, with the aim of enhancing wellbeing from a positive psychology perspective. The current controlled study was designed to establish the effectiveness of an 8-week online mindfulnessbased character strengths practice (MBSP) on wellbeing, for the general population. Nineteen participants completed the MBSP programme, and 20 participants were placed in a nointervention control group. Self-report questionnaires, including Satisfaction With Life Scale, Flourishing Scale, Positive Psychotherapy Inventory, and a Signature Strengths Inventory Scale, were used to evaluate the levels of wellbeing and flourishing pre- and post-intervention. Wilcoxon signed-rank tests found that MBSP participants scored significantly higher in all four measures post-MBSP, whereas participants in the control group did not, with the only exception of a slight increase in satisfaction with life scores. The study found MBSP to be the first PPI programme aimed at the general population, which explicitly focuses on character strengths to elicit significant positive changes and increase levels of wellbeing. Given our preliminary results, larger samples utilising randomised control trial methods should attempt to confirm these preliminary findings. The programme's future is promising, since its application appears to have great potential to positively influence people's lives, thus moving closer to the goal of increasing societal flourishing.
\end{abstract}

Keywords: Mindfulness-Based Strengths Practice, positive psychology intervention, mindfulness, character strengths

\section{Introduction}

Within the field of positive psychology, the topics of mindfulness and character strengths have become two of the most significant resources for achieving optimal human functioning (Niemiec, Rashid, \& Spinella, 2012). Either of these two elements is capable of being heightened individually (Hart, Ivtzan, \& Hart, 2013). However, despite theoretical and conceptual overlap (Niemiec et al., 2012), these drivers of human flourishing (or eudaimonic wellbeing) have only ever been applied separately. Consequently, there is great potential to create a PPI by intertwining these two elements with the aim of enhancing wellbeing, as opposed to more typical interventions in psychology which often aim at fixing or alleviating problems (Sin \& Lyubomirsky, 2008). In response to this, Niemiec (2014) has recently developed a PPI aimed at the general population, known as the Mindfulness-Based Strengths Practice (MBSP). 


\subsection{Mindfulness}

The study of mindfulness within social sciences has increased significantly in recent years (Cullen, 2011; Sears, Tirch, \& Denton, 2011). The practice of mindfulness is derived from ancient Buddhist meditation, which used to be practised over 2,500 years ago; mindfulness meditation is also known as "insight meditation" (Ivtzan, Gardner, \& Smailova, 2011). This meditation is described as the experience of consciously attempting to focus attention on the present moment in a non-judgmental manner, where one attempts not to dwell on discursive, ruminating thoughts, and puts past and future thought distractions aside (Shapiro, 1982). Moreover, mindfulness is often equated interchangeably with practices to achieve such a state of nonjudgmental presence; however, mindfulness can be applied to any moment-to-moment experience, so much so that it has been described as a "way of being" (Kabat-Zinn, 1994).

To date, a variety of programmes (or interventions) utilising mindfulness - known as mindfulness-based interventions (MBIs) - have been developed, amidst a growing interest in this contemplative practice. For example, the most notable mindfulness programme, MindfulnessBased Stress Reduction programme (MBSR) (Kabat-Zinn, 1982, 2003), was the subject of a literature review of research papers from four of the largest peer-reviewed health science databases (EBSCO, Cinahl, Psychline, and Medline), which found MBSR to be an effective treatment for daily life stress and stress-related symptoms (Praissman, 2008). Apart from MBSR, further meta-analyses support the benefits of other general mindfulness interventions for reducing symptoms of anxiety and depression (Fjorback, Arendt, Ørnbøl, Fink, \& Walach, 2011; Hofmann, Sawyer, Witt, \& Oh, 2010), including Acceptance and Commitment Therapy (ACT) (Hayes, Strosahl, \& Wilson, 1999), Mindfulness-Based Cognitive Therapy (MBCT) (Segal, et al., 2002) and Dialectical Behaviour Therapy (DBT) (Linehan, 1993). There are many more MBIs out there, most existing with the aim of repairing physical and/or mental health conditions (Cullen, 2011).

PPIs are defined as interventions with a clear goal and intention to increase positive variables (Parks \& Biswas-Diener, 2013). As such, most of the popular MBIs do not fit the framework of PPIs, as they aim at decreasing negative variables. Therefore, a limitation with MBIs is that, although positive effects on wellbeing have been found, their main focus tends to be primarily around the aim of alleviating problems and symptoms for specific issues, such as stress, anxiety, and depression, instead of promoting wellbeing for a broader population (Goyal et al., 2014; Lindsay \& Creswell, 2015). Ivtzan et al (in press) offer an in-depth discussion of the meeting point between mindfulness and positive psychology, highlighting the fact that mindfulness is primarily used to alleviate deficiencies, while its potential to enhance positive variables is largely disregarded. Interestingly, many positive associations have been found between mindfulness and wellbeing from a range of studies and populations, including: subjective wellbeing, positive affect, life satisfaction, psychological wellbeing, optimism, self-regulation, self-compassion, positive relationships, vitality, creativity, health, longevity and a range of cognitive skills (e.g., Brown \& Kasser, 2005; Baer, Smith, \& Allen, 2004; Keng, Smoski, \& Robins, 2011; Carson, Carson, Gil, \& Baucom, 2004). Hence, what is missing are tested and validated MBI programmes that primarily focus on promoting wellbeing and flourishing, that is to say, MBIs that could be defined as PPIs, aimed at the general non-clinical population.

\subsection{Character strengths}

Another influential positive psychology tool, and arguably the backbone of the field of positive psychology, is character strengths. A decade ago, Peterson and Seligman (2004) set out to establish a universal framework to describe and measure the strengths and virtues that exemplify 
good character and human goodness. The result was the VIA (Values-In-Action) classification of strengths, a universally valid classification system devised of 24 character strengths categorised into a six-virtue categorisation: courage, humanity, justice, temperance, transcendence, and wisdom (Dahlsgaard, Peterson, \& Seligman, 2005).

The tool used to explore and measure these is the VIA classification, known as the VIA-IS. These virtues have now become common language used to describe the psychological ingredients of what is best in people (Niemiec, 2012). Hence, the VIA classification is now contrasted to the traditional psychology classification systems, which have focused on illness and disease (e.g., DSM-V; American Psychiatric Association, 2013). The creation of the VIA-IS has consequently become a popular tool among practitioners, therapists, and consultants.

Character strengths can be likened to trait-based personality types; however, they are slightly less stable, since they vary in degree within particular life domains, such as work and family (Seligman \& Peterson, 2004). Ultimately, character strengths are those unique human qualities, which all of us possess, that can be cultured and developed in consideration of the context one is in (Biswas-Diener, Kashdan, \& Minhas, 2011). The understanding of character strengths is important for any individual because they define who we are - highlighting our authentic self, or, put differently, our unique "identity." This is most clearly demonstrated by those character strengths which come most naturally to us - known as our "signature strengths."

A recent empirical review of research from the last 10 years examining character strengths (using the VIA classification system) has highlighted many associations between character strengths and positive outcomes (Niemiec, 2013). For example, research has suggested a strong association between specific character strengths and satisfaction with life (SWL), while a greater overall score of all 24 character strengths has been correlated with subjective wellbeing (SWB) (Ruch, Huber, Beermann, \& Proyer, 2007). Furthermore, research has investigated which character strengths are associated with life satisfaction (Brdar \& Kashdan, 2010), and which buffer us in times of poor physical and psychological wellness (Peterson, Park, \& Seligman, 2006).

Research by Seligman, Steen, Park and Peterson (2005), investigating original PPIs, has demonstrated the positive benefits of signature strengths being used as an intervention. The study found that inviting people to use their signature strengths in new and different ways for a number of days led to significant increases in the levels of happiness, and decreases in depressive symptoms. These effects were sustained at a six-month follow-up, and the overall findings have been more recently supported (Mongrain \& Anselmo-Matthews, 2012). Further research has confirmed that having character strength knowledge and using one's signature strengths are associated with greater SWB and psychological wellbeing (PWB) (Govindji \& Linley, 2007; Linley, Nielsen, Gillett, \& Biswas-Diener, 2010). Therefore, compared to the mindfulness literature, character strengths are being used as a PPI; however, there is yet to be a programme devoted to exploring character strengths in the general population to build components of human flourishing and wellbeing.

\subsection{Mindfulness and character strengths}

Looking at how mindfulness and character strengths are connected, simply by exploring the definition of mindfulness in more detail, a strong relationship between the two clearly emerges (Coffey, Hartman, \& Fredrickson, 2010). Bishop et al. (2004) define mindfulness through two core elements, which are based upon two character strengths. The first element of mindfulness describes the practice of attention focus, based upon the character strength of self-regulation for attending to the specific moment. The second element of mindfulness refers to the nonjudgmental quality of that focused attention, grounded on the strength of curiosity to allow for 
an attitude of openness and acceptance. Moreover, in the original VIA classification work (Peterson \& Seligman, 2004), reference was given to mindfulness trainings and to the temperance and courage virtues (Niemiec, 2012).

Research exploring the links between mindfulness and character strengths is rather limited. One study has found that the more time one spends using their character strengths, the greater levels of mindfulness one has (Jarden et al., 2012). Further research studies have found that the character strengths of creativity and judgment correlated with mindfulness (Sugiura, 2004), and that hope/optimism increased as a result of mindfulness practice (Carson et al., 2004).

Theoretically, little has been discussed about the overall integration and mutual impact of mindfulness and character strengths. Baer (2009) proposed that mindfulness meditation could facilitate the cultivation of strengths and could increase wellbeing. Another and more recent suggestion, speaking of this connection, describes how the Five Mindfulness Trainings, Reverence for Life, True Happiness, True Love, Loving Speech and Deep Listening, and Nourishment and Health, of Thich Nhat Hanh (Nhat Hanh, 1993; Nhat Hanh \& Cheung, 2010), can be connected with character strengths (see Niemiec, 2012). Niemiec (2012) examined each training, suggesting that character strengths could promote mindful living. For example, the training of Loving Speech and Deep Listening, underpinning and being used in conjunction with compassion/kindness, can deepen the experience of relationships.

Niemiec, Rashid, and Spinella (2012) have explained how these two elements of mindfulness and strengths have the potential for growth and self-improvement; they also highlighted more explicitly how a connection between them does exist. They argue that there is potential for integrating the two practices together to create a virtuous circle of positive impact or, as they allude to, an upward positive spiral (Fredrickson, 2001). By this, they explain how mindfulness can help one to express their character strengths in a way that is balanced and is sensitive to the context they are in. Also, they illustrate how character strengths can bolster an individual's mindfulness practice by overcoming typical obstacles and distractions, thus enhancing mindfulness (Niemiec, 2014).

\subsection{Mindfulness-based Strengths Practice (MBSP)}

Merging the conceptual links of mindfulness and character strengths, Niemiec (2014) developed the Mindfulness-Based Strengths Practice (MBSP), a programme designed to explicitly focus on what is best in people. The MBSP practice involves meditations, exercises, and discussions to encourage participants to enhance their engagement with life to increase levels of wellbeing (Niemiec et al., 2013). The programme is built upon Thich Nhat Hanh's mindfulness work, which is based on mindful living (Nhat Hanh, 1993); on the other hand, it is grounded within the character strength research developed by Seligman and Peterson (2004). The unique aspect of MBSP is how mindfulness is combined with strengths, providing a unique synergy between these two forces of positive psychology (Niemiec, 2013).

In essence, MBSP operates from four universal assumptions of human beings (Niemiec, 2014). Firstly, individuals have the power to build their character strengths and mindfulness. Secondly, people can use their mindfulness ability and their character strengths to deepen selfawareness, foster insight, build a life of meaning and purpose, form relationships, and reach their goals. Thirdly, individuals who practise MBSP can use their core qualities in a more balanced and proficient manner. Fourth and finally, applying character strengths to mindfulness practice and mindful living will encourage individuals to become more consistent, as well as enable them to reap more benefits from their mindfulness practice. 


\subsection{The present study}

Despite promising pilot data for MBSP as a PPI (Niemiec \& Lissing, 2016; Niemiec, 2014), further research is required to test the effectiveness of the programme. The objective of the current study was to demonstrate that participants who completed the MBSP programme would have greater levels of wellbeing and flourishing than those in a no-intervention control group. The hypothesis was that participants in the MBSP group would show higher levels of wellbeing, as predicted by higher scores on the Satisfaction With Life Scale (SWLS), Flourishing Scale (FS), the Positive Psychotherapy Inventory, and the Signature Strengths Inventory (SSI), compared to participants in the control group.

\section{Method}

\subsection{Participants and design}

The study used a control design consisting of one experimental MBSP group and one nointervention control group. Participants in the experimental condition $(n=19)$ completed the 8week programme and those in the control condition $(n=20)$ did not receive any intervention. All participants were recruited from the general adult population, with an inclusion criterion of 18 years and above. Participants in the MBSP group were recruited online via the VIA Institute's website, which advertised the 8 -week MBSP programme to the general public. The control group was also recruited from the general population, an opportunity sample, in the UK. The mean age of those in the MBSP group was $50.24(S D= \pm 6.97$, range $=30$ or $31-70)$, with seven $(37 \%)$ male and $12(63 \%)$ female participants. The mean age of participants in the control group was 49.30 $(S D= \pm 8.37$, range $=25)$, with nine $(45 \%)$ male and $11(55 \%)$ female participants.

Ethical approval for the control group was gained from the University of East London's research ethics committee, and the MBSP sample was ethically approved by the VIA Institute. The leading practitioner of the MBSP was an experienced individual who had vast knowledge about mindfulness and character strengths. This person was also capable of safely guiding participants through personal exploration and potentially life-changing exercises. Participants in the control group did not complete the MBSP but were offered a VIA Me report (character strengths report offered by VIA Institute, worth USD20) as a participation gift, and were also supplied with further information regarding the MBSP programme. All participants were over the age of 18 and were able to give full consent to answering the self-report measures online, where their anonymity was protected and their answers were kept confidential. All participants understood their right to withdraw throughout the research process, and during the study no ethical issues were raised.

\subsection{Measures}

Four self-report measures were used to assess participants' levels of happiness, flourishing, engagement and signature strengths use.

Satisfaction With Life Scale (SWLS: Diener, Emmons, Larsen, \& Griffin, 1985) is a five-item selfreport measure of global life satisfaction. Participants respond on a 7-point Likert scale ("Strongly Disagree" to "Strongly Agree") to each item (e.g., "I am satisfied with my life"). A higher overall score of the measure indicates a higher global life satisfaction. The SWLS has strong internal reliability $(r=.87)$ and moderate temporal stability, as indicated by test-retest reliability $(\mathrm{r}=.82)$ (Diener et al., 1985). The scale has been widely used and has demonstrated good psychometric properties across many studies (Diener et al., 1985; Diener, Scollon, Oishi, Dzokoto, \& Suh, 2000). 
Flourishing Scale (Diener, Lucas, Schimmack, \& Helliwell, 2009) is an eight-item measure designed to assess participants' self-perceived success in areas identified as important for psychological flourishing, including relationships, meaning, purpose, self-esteem, and optimism. This scale captures eudaimonic or psychological dimensions of wellbeing, such as the need for competence, relatedness, and self-acceptance (Ryff, 1989; Ryan \& Deci, 2001) which are essential for enabling optimal human functioning. Each item is phrased in a positive direction and the answers are measured on a Likert scale ranging from 1 (strongly disagree) to 7 (strongly agree). A high score on the scale indicates respondents have a positive self-image in important areas of functioning (Diener et al., 2010). The scale has a Cronbach's alpha of .86 and temporal stability over a 1-month period $(r=.71 ., N=261, p<.001)$ (Diener et al., 2010).

Engagement is an important element relating to using one's strengths to live a more absorbing life, and, ultimately, a flourishing life. This was measured using the Positive Psychotherapy Inventory (Rashid, 2008), which includes several questions on the pleasant life, the meaningful life, and the engaged life. For the purposes of this study, the seven items in relation to the engaged life were presented, where participants were asked to state how much they agreed with the statements on a 4-point scale ranging from 0 to 3 . A total score for engagement was calculated from the seven questions relating to knowledge, activities, problem-solving, concentration, flow, management, and accomplishment.

There are measures of strengths use in the literature (e.g., Wood et al., 2011); however, none target the use of signature strengths (i.e., those character strengths most essential or central to who the person is). Therefore, four questions on signature strengths use were used, courtesy of the VIA Institute on Character. This will be referred to as the Signature Strengths Inventory (SSI), which has not been previously validated. These questions include: 1) Signature strengths/flourishing link (i.e. "My greatest fulfilments in life occur when I express those parts of myself that are core to who I am"), 2) Signature strengths - work (i.e. "My work is an expression of who I am at my core, not just something I do well"), 3) Signature strengths relationships (i.e. "My personal relationships give me the opportunity to express the best parts of myself") 4) Signature strengths - community (i.e. "My activities in my community are vehicles by which I express my best self"). Participants scored on a 5-point Likert scale from 1-5 ("Strongly Disagree" to "Strongly Agree"), where higher scores indicate greater use of their signature strengths.

\subsection{Procedure and apparatus}

Two MBSP groups performed one after another, spaced over a period of a few months. Participants selected their preferred programme date; the first group had nine participants and the second had 10. Once the first MBSP group had finished its final weekly session, the second group began its first session. It should be stated that not all participants in the MBSP condition completed all eight sessions. Of the 19 participants, 13 completed all eight sessions, five completed seven sessions, and one completed six sessions.

All participants completed the short self-report questionnaires online via email at preintervention (baseline), and, after an 8-week period (post-intervention), participants were contacted again via email to re-complete the measures and to send them back by email to the researcher. The data collected included participants' age, gender, and scores of the four selfreport measures: Satisfaction with Life, Flourishing Scale, Engagement, and Signature Strengths use. It took an average of five minutes to complete all the self-report measures.

The intervention programme for this study was executed online. There is growing evidence in support of online/web-based mindfulness interventions (Krusche et al., 2012). Studies using 
online mindfulness interventions revealed a variety of benefits, including improvements to wellbeing (Mak et al., 2015), resilience, and vigour (Aikens et al., 2014), reduced stress, anxiety, and depression (Cavanagh et al., 2013), and improved happiness, quality of life, and flourishing (Feicht et al., 2013), compared to control groups.

MBSP: Participants in the MBSP condition logged in each week online, using a password, via the eMindful platform, to connect to the practitioner and the other participants in the group session. The sessions each lasted two hours, consisting of a variety of exercises and practices, similar to other mindfulness-based programmes such as the MBSR, which is also available online. Each of the sessions followed the same key structure, which included: an opening meditation, character strengths breathing space, dyads or group discussion reviewing the practice of mindfulness and strengths, a review of previous sessions (what went well) and set homework exercises, introduction to new material, an experiential mindfulness-based character strengths exercise, a virtue circle (or debrief) discussion, suggested homework exercises for the next session, and finally closing with a character strengths reflection.

Each session was built around a centerpiece exercise that was unique to that session. Week 1: Participants were invited to engage in a practical experience, where they approached an object (a raisin) as if they were encountering it for the very first time, an exercise pioneered by KabatZinn (1990). Week 2: The group identified their unique character strengths by engaging with the VIA character strengths, as well as spotting strengths in stories. Week 3: Participants performed a statue meditation, whereby they experienced the application of integrating mindfulness and character strengths, learning about obstacles to mindfulness and how character strengths use could deepen the experience of mindfulness practice. Week 4: The main exercise was a mindful walk, where participants gained insight into how mindfulness could be incorporated into daily life and how character strengths could be easily embedded into many daily activities. Week 5: The session's centerpiece was a loving-kindness meditation, which was followed by a strengthexploration meditation that demonstrated to the participants how specific character strengths could be targeted and built within meditation. Week 6: Participants engaged in a character strengths 360 review, whereby they were given awareness of their signature strengths, unrecognised strengths, weaker strengths, and strengths with potential to work on. Using meditation, participants saw how they could reframe and manage any issues they might have had. Week 7: Using the best possible self-exercise, participants were able to see how the MBSP programme could guide future plans and goals. Week 8: Participants shared their best personal bits together, highlighting what they had learnt from the programme and the potential areas of growth they had experienced.

\section{Results}

To examine the effect of the 8-week MBSP programme, participants' scores at baseline and after the 8-week period were inputted and analysed in an SPSS 20 software package. A KolomogorovSmirnov test of normality was conducted and histograms were produced, which found that there was no homogeneity of variance between the datasets from the two groups. Therefore, the requirements for conducting parametric independent sample t-tests between the two conditions were not justified. Owing to the skewed baseline data between the two conditions, only statistical comparisons could be made between pre- and post-intervention within the two groups. As a result, non-parametric Wilcoxon signed-rank tests were conducted to test the hypothesis of whether the MBSP programme would increase wellbeing, engagement, and signature strengths use. 
Table 1. Mindfulness-Based Strengths Practice participants' and control group participants' wellbeing scores

\begin{tabular}{lcccc}
\hline \multirow{2}{*}{ Measure } & \multicolumn{2}{c}{ Baseline } & \multicolumn{2}{c}{ Post-test } \\
\cline { 2 - 5 } & Median & Int. quartile range & Median & Int. quartile range \\
\hline MBSP Group & & & & \\
$\quad$ SWL & 28.00 & $25.00-30.00$ & 30.00 & $28.00-33.00$ \\
$\quad$ FS & 49.00 & $47.00-51.00$ & 51.50 & $49.50-55.00$ \\
$\quad$ Engagement & 17.00 & $14.00-19.00$ & 18.00 & $16.00-20.25$ \\
$\quad$ SSI & 17.00 & $15.00-18.00$ & 18.00 & $18.00-19.00$ \\
No Intervention Group & & & & \\
$\quad$ SWL & 26.50 & $19.50-29.00$ & 28.00 & $21.00-29.00$ \\
$\quad$ FS & 44.00 & $40.50-48.75$ & 45.00 & $41.25-48.00$ \\
$\quad$ Engagement & 15.00 & $12.00-16.00$ & 14.50 & $12.00-17.00$ \\
$\quad$ SSI & 15.00 & $13.25-15.00$ & 15.00 & $14.00-15.75$ \\
\hline
\end{tabular}

Note. SWLS = Satisfaction With Life Scale; FS = Flourishing Scale; Engagement = the Engagement section of the Positive Psychotherapy Inventory; SSI = Signature Strengths Inventory.

Table 1 above shows the median scores from the two sample groups on the four wellbeing measures at baseline and 8 weeks later. The MBSP group had an overall increase in the average scores for all four of the wellbeing measures. Wilcoxon signed-rank tests demonstrating the exact one-tailed significance showed that the 8-week MBSP programme did elicit statistically significant changes and medium-to-large effect sizes in all four measures, including: SWL scores from pre $($ Median $=28.00)$ to post-intervention (Median $=30.00), z=-2.54, p=.004, r=0.41$, FS scores from pre (Median $=49.00$ ) to post-intervention (Median $=51.50), z=-2.64, p=.003, r=0.62$, Engagement scores from pre (Median $=17.00)$ to post-intervention (Median $=18.00), z=-2.62, p$ $=.003, \mathrm{r}=0.62$, and SSI scores from pre (Median $=17.00)$ to post $($ Median $=18.00), \mathrm{z}=2.41, \mathrm{p}=$ $.008, \mathrm{r}=0.57$. The significant differences between pre- and post-intervention measures and the large effect sizes suggest that the MBSP did elicit post-intervention positive impact on wellbeing, thus supporting the hypothesis that the MBSP programme would increase wellbeing.

Further analysis was conducted on the control group to see if there were any differences in pre- and post-intervention scores after the 8-week period. Using Wilcoxon signed-rank tests, it was found that for three out of the four measures there were no significant differences: FS scores from pre- $($ Median $=44.00)$ to post-intervention $($ Median $=45.00), \mathrm{z}=-1.00, \mathrm{p}=.157, \mathrm{r}=0.22$, Engagement scores from pre- (Median $=15.00$ ) to post-intervention (Median $=14.50), z=-0.44, p$ $=.347, \mathrm{r}=0.10$, SSI scores from pre- (Median $=15.00)$ to post-intervention (Median $=15.00), \mathrm{z}=-$ $.672, \mathrm{p}=.275, \mathrm{r}=0.15$. However, for SWL, a significant difference was found between pre(Median $=26.50$ ) and post-intervention (Median $=28.00), \mathrm{z}=-2.05, \mathrm{p}=.023, \mathrm{r}=0.50$ measures.

\section{Discussion}

Statistical analysis of the MBSP group has successfully shown a significant difference between participants' scores at baseline, compared to post-programme scores. This indicates that the MBSP has a positive impact on wellbeing. However, the lack of homogeneity of variance between the two groups should be taken into consideration, and caution should be exercised when interpreting the results. Participants in the control group did not have any statistical differences in three out of the four measures; however, this support is slightly hindered, since SWL scores increased after the 8-week period. Overall, the research findings support the hypothesis that the 
MBSP programme does positively increase levels of wellbeing, including SWL, flourishing, engagement, and signature strengths use, and is therefore applicable as a PPI for the general population. Therefore, these initial findings do suggest relevance and positive implications for the potential of the MBSP to boost levels of flourishing. These findings will be examined in more detail, and will be followed by some limitations of the study and future research directions.

This study offers initial suggestions that finding one's character strengths through exercises, such as the character strengths 360, helps individuals to gain insight into their set of character strengths. By understanding which character strengths allow one to be their best (signature strengths) and also to raise awareness of those that they do not engage with regularly (wider strengths spotting), individuals' wellbeing can be positively enhanced. Additionally, by using mindfulness to identify the "golden mean," namely, to which degree, and which potential combinations of character strengths could apply to appropriate situations (Linley, 2008; Niemiec, 2014), individuals become more savvy about living life to their full potential. Overall, the online programme of MBSP drew positive effects, becoming the first MBI to utilise character strengths, and enabling participants to learn and engage with this language and practice to improve levels of wellbeing and flourishing.

The study also supports the body of research on mindfulness which suggests that this practice is correlated with positive wellbeing effects (Brown \& Kasser, 2005; Shapiro et al., 2008; Carson $t$ al., 2004). However, this research has demonstrated that MBSP is the first validated MBI programme which utilises signature strengths to build positive outcomes, supporting the research that character strengths use does enhance wellbeing in the form of SWL (Linley et al., 2010; Mongrain \& Anselmo-Matthews, 2009; Peterson \& Peterson, 2008; Seligman et al., 2005).

Whilst the overall findings from the control group do enhance the suggestion that MBSP is a worthwhile and successful PPI, there are a number of limitations that would have to be taken into account. Participants in the control group did increase in SWL. However, there are reasons which could potentially explain this increase. Firstly, SWL, as a measure of happiness, is argued by some to be a less stable measure of assessment, whereby current moods and life circumstances may possibly change over a relatively short period of time (Yardley \& Rice, 1991). However, this appears to be unlikely, since the current mood has been shown to have little to no effect on one's overall judgment of life satisfaction (Pavot \& Diener, 2008). Moreover, the SWLS has displayed high levels of internal consistency in previous research (Diener et al., 2000).

A second potential reason is that the simple process of monitoring one's happiness, namely, by completing a scale, may have acted as an intervention in itself, increasing participants' scores on this SWB measure. Therefore, it is possible that control participants experienced a boost in subjective wellbeing because of these reasons. Other limitations to consider include the lack of longitudinal data; future studies could test the programme's impact at 1 month and 6 months following the programme's end, to see whether or not the positive influence is maintained throughout time. One final limitation is the small sample size; future studies could follow up with a larger sample size that would make it easier to confirm the programme's effect on wellbeing.

To further examine the potential of MBSP as a wider intervention, the implementation of different scales into the research design would enable the examination of MBSP to help individuals deal with deficiencies and psychological distress. This is highlighted because the MBSP does also have a focus on helping individuals with these matters (not just PPI aims). One only has to examine session 6 of the MBSP programme to see that the exercises are aimed at resolving and managing difficulties as well (Niemiec, 2014). Therefore, MBSP could also be 
empirically tested to see if it can reliably lead to a decrease in these negative life components, as well as a boost in positive life components.

While this study did not examine mechanisms of action, MBSP offers unique perspectives that warrant future investigation. This includes an evaluation of if and how mindfulness is able to enhance character strengths use (i.e., "mindful strengths use"), and if and how character strengths use, in turn, can enhance and enliven mindfulness (i.e., referred to as "strong mindfulness") (Niemiec, 2014). Additional research should also examine the effects of MBSP over a longer timescale using larger sample sizes, possibly investigating different populations, such as schools and businesses, and using randomised control trials.

\section{Authors}

Itai Ivtzan

University of East London

i.ivtzan@uel.ac.uk

Ryan M. Niemiec

VIA Institute on Character

Charlie Briscoe

University of East London

\section{Publishing Timeline}

Received 25 August 2016

Accepted 28 August 2016

Published 14 September 2016

\section{References}

Aikens, K. A., Astin, J., Pelletier, K. R., Levanovich, K., Baase, C. M., Park, Y. Y., \& Bodnar, C. M. (2014). Mindfulness goes to work: Impact of an online workplace intervention. Journal of Occupational $\mathcal{E}$ Environmental Medicine, 56(7), 721-731. http://dx.doi.org/10.1097/JOM.0000000000000209

American Psychiatric Association. (2013). Diagnostic and statistical manual of mental disorders (5th ed.). Arlington, VA: American Psychiatric Publishing.

Baer, R. A., Smith, G. T., \& Allen, K. B. (2004). Assessment of mindfulness by self-report: The Kentucky Inventory of Mindfulness Skills. Assessment, 11, 191-206. http://dx.doi.org/10.1177/1073191104268029

Baer, R. A. (2009). Self-focused attention and mechanisms of change in mindfulness based treatment. Cognitive Behaviour Therapy, 38(1), 15-20. http://dx.doi.org/10.1080/16506070902980703

Bishop, S. R., Lau, M., Shapiro, S. L., Carlson, L., Anderson, N. D., \& Carmody, J. (2004). Mindfulness: A proposed operational definition. Clinical Psychology: Science and Practice, 11(1), 230-241. http://dx.doi.org/10.1093/clipsy.bph077

Biswas-Diener, R., Kashdan, T. B., \& Minhas, G. (2011). A dynamic approach to psychological strength development and intervention. Journal of Positive Psychology, 6(2), 106-118. http://dx.doi.org/10.1080/17439760.2010.545429

Brdar, I., \& Kashdan, T. B. (2010). Character strengths and wellbeing in Croatia: An empirical investigation of structure and correlates. Journal of Research in Personality, 44, 151-154. http://dx.doi.org/10.1016/j.jrp.2009.12.001

Brown, K. W., \& Kasser, T. (2005). Are psychological and ecological wellbeing compatible? The role of values, mindfulness, and lifestyle. Social Indicators Research, 74, 349-368. http://dx.doi.org/10.1007/s11205-004-8207-8

Carson, J. W., Carson, K. M., Gil, K. M., \& Baucom, D. H. (2004). Mindfulness-based relationship enhancement. Behavior Therapy, 35(3), 471-494. http://dx.doi.org/10.1016/S0005-7894(04)80028-5 
Cavanagh, K., Strauss, C., Cicconi, F., Griffiths, N., Wyper, A., \& Jones, F. (2013). A randomised controlled trial of a brief online mindfulness-based intervention. Behavior Research Therapy, 51(9), 573578. http://dx.doi.org/10.1016/j.brat.2013.06.003

Coffey, K. A., Hartman, M., \& Fredrickson, B. L. (2010). Deconstructing mindfulness and constructing mental health: Understanding mindfulness and its mechanisms of action. Mindfulness, 1(4), 235-253. http://dx.doi.org/10.1007/s12671-010-0033-2

Cullen, M. (2011). Mindfulness-based interventions: An emerging phenomenon. Mindfulness, 2(1), 186193. http://dx.doi.org/10.1007/s12671-011-0058-1

Dahlsgaard, K., Peterson, C., \& Seligman, M. E. P. (2005). Shared virtue: The convergence of valued human strengths across culture and history. Review of General Psychology, 9(3), 203-213. http://dx.doi.org/10.1037/1089-2680.9.3.203

Diener, E., Emmons, R., Larsen, J., \& Griffin, S. (1985). The Satisfaction With Life Scale. Journal of Personality Assessment, 49(1), 71-75. http://dx.doi.org/10.1207/s15327752jpa4901 13

Diener, E., Lucas, R., Schimmack, U., \& Helliwell, J. (2009). Wellbeing for public policy. New York, NY: Oxford University Press. http://dx.doi.org/10.1093/acprof:oso/9780195334074.001.0001

Diener, E., Scollon, C. K. N., Oishi, S., Dzokoto, V., \& Suh, E. M. (2000). Positivity and the construction of life satisfaction judgements: Global happiness is not the sum of its parts. Journal of Happiness Studies, 1, 159-176. http://dx.doi.org/10.1023/A:1010031813405

Diener, E., Wirtz, D., Tov, W., Kim-Prieto, C., Choi, D. W., Oishi, S., \& Biswas Diener, R. (2010). New wellbeing measures: Short scales to assess flourishing and positive and negative feelings. Social Indicator Research, 97, 143-156. http://dx.doi.org/10.1007/s11205-009-9493-y

Feicht, T., Wittmann, M., Jose, G., Mock, A., von Hirschhausen, E., \& Esch, T. (2013). Evaluation of a seven-week web-based happiness training to improve psychological wellbeing, reduce stress, and enhance mindfulness and flourishing: A randomized controlled occupational health study. EvidenceBased Complementary and Alternative Medicine, 2013, 1-14. http://dx.doi.org/10.1155/2013/676953

Fjorback, L. O., Arendt, M., Ørnbøl, E., Fink, P., \& Walach, H. (2011). Mindfulness-based stress reduction and mindfulness-based cognitive therapy - a systematic review of randomized controlled trials. Acta Psychiatrica Scandinavica, 124, 102-119. http://dx.doi.org/10.1111/j.1600-0447.2011.01704.x

Fredrickson, B. L. (2001). The role of positive emotions in positive psychology: The broaden-and-build theory of positive emotion. American Psychologist, 56, 218-226. http://dx.doi.org/10.1037/0003066X.56.3.218

Glück, J., \& Baltes, P. B. (2006). Using the concept of wisdom to enhance the expression of wisdom knowledge: Not the philosopher's dream but differential effects of developmental preparedness. Psychology and Aging, 21, 679-690. http://dx.doi.org/10.1037/0882-7974.21.4.679

Govindji, R., \& Linley, P. A. (2007). Strengths use, self-concordance and wellbeing: Implications for strengths coaching and coaching psychologists. International Coaching Psychology Review, 2(2), 143153.

Goyal, M., Singh, S., Sibinga, E. M., Gould, N. F., Rowland-Seymour, A., Sharma, R., et al. (2014). Meditation programs for psychological stress and wellbeing: A systematic review and meta-analysis. JAMA Internal Medicine, 174(3), 357-68. http://dx.doi.org/10.1001/jamainternmed.2013.13018

Hart, R., Ivtzan, I., \& Hart, D. (2013). Mind the gap in mindfulness research: A comparative account of the leading schools of thought. Review of General Psychology, 17(4), 453-466. http://dx.doi.org/10.1037/a0035212

Hayes, S. C., Strosahl, K., \& Wilson, K. G. (1999). Acceptance and commitment therapy: An experiential approach to behavior change. New York, NY: Guilford Press.

Ivtzan, I., Gardner, H. E., \& Smailova, Z. (2011). Mindfulness meditation and curiosity: The contributing factors to wellbeing and the process of closing the self-discrepancy gap. International Journal of Wellbeing, 1(3), 316-326. http://dx.doi.org/10.5502/ijw.v1i3.2

Ivtzan, I., Young, T., Martman, J., Jeffrey, A., Lomas, T., Hart, R., \& Eiroa-Orosa, F. J. (in press). Integrating mindfulness into positive psychology: A randomised controlled trial of an online positive mindfulness program. Mindfulness. http://dx.doi.org/10.1007/s12671-016-0581-1 
Jarden, A., Jose, P., Kashdan, T., Simpson, O., McLachlan, K., \& Mackenzie, A. (2012). [International Wellbeing Study]. Unpublished raw data.

Kabat-Zinn, J. (1990). Full catastrophe living: How to cope with stress, pain and illness using mindfulness meditation. New York, NY: Delacorte.

Kabat-Zinn, J. (1994). Wherever you go, there you are. New York, NY: Hyperion.

Kabat-Zinn, J. (2003). Mindfulness-based interventions in context: Past, present, and future. Clinical Psychology: Science and Practice, 10, 144-156. http://dx.doi.org/10.1093/clipsy.bpg016

Krusche, A., Cyhlarova, E., King, S., \& Williams, J. M. G. (2012). Mindfulness online: A preliminary evaluation of the feasibility of a web-based mindfulness course and the impact on stress. British Medical Journal, 2(3), e000803.

Lindsay, E. K., \& Creswell, J. D. (2015). Back to the basics: How attention monitoring and acceptance stimulate positive growth. Psychological Inquiry, 26(4), 343-348. http://dx.doi.org/10.1080/1047840X.2015.1085265

Linehan, M. (1993). Skills training manual for treating borderline personality disorder. New York, NY: Guilford Press.

Linley, P. A. (2008). Average to A+. Coventry, England: CAPP Press.

Linley, P.A., Nielsen, K. M., Wood, A. M., Gillett, R., \& Biswas-Diener, R. (2010). Using signature strengths in pursuit of goals: Effects on goal progress, need satisfaction, and wellbeing, and implications for coaching psychologists. International Coaching Psychology Review, 5(1), 8-17.

Mak, W. W., Chan, A. T., Cheung, E. Y., Lin, C. L., \& Ngai, K. C. (2015). Enhancing web-based mindfulness training for mental health promotion with the health action process approach: Randomized controlled trial. Journal of Medical Internet Research, 17(1):e8. http://dx.doi.org/10.2196/jmir.3746

Mongrain, M., \& Anselmo-Matthews, T. (2012). Do positive psychology exercises work? A replication of Seligman et al. Journal of Clinical Psychology, 68(4), 382-389. http://dx.doi.org/10.1002/jclp.21839

Niemiec, R. M. (2012). Mindful living: Character strengths interventions as pathways for the five mindfulness trainings. International Journal of Wellbeing, 2(1), 22-33. http://dx.doi.org/10.5502/ijw.v2i1.2

Niemiec, R. M. (2013). VIA character strengths: Research and practice (The first 10 years). In H. H. Knoop \& A. Delle Fave (Eds.), Wellbeing and cultures: Perspectives on positive psychology (pp. 11-30). New York. NY: Springer. http://dx.doi.org/10.1007/978-94-007-4611-4_2

Niemiec, R. M. (2014). Mindfulness and character strengths: A practical guide to flourishing. Cambridge, MA: Hogrefe.

Niemiec, R. M., \& Lissing, J. (2016). Mindfulness-based strengths practice (MBSP) for enhancing wellbeing, life purpose, and positive relationships. In I. Ivtzan \& T. Lomas (Eds.), Mindfulness in positive psychology: The science of meditation and wellbeing (pp. 15-36). New York, NY: Routledge.

Niemiec, R. M., Rashid, T., \& Spinella, M. (2012). Strong mindfulness: Integrating mindfulness and character strengths. Journal of Mental Health Counseling, 34(3), 240-253.

http://dx.doi.org/10.17744/mehc.34.3.34p6328x2v204v21

Nhat Hanh, T. (1993). For a future of the Buddha's teaching. New York, NY: Broadway.

Nhat Hanh, T., \& Cheung, L. (2010). Savor: Mindful eating, mindful life. New York, NY: HarperCollins.

Park, N., Peterson, C., \& Seligman, M. E. P. (2004). Strengths of character and wellbeing. Journal of Social E Clinical Psychology, 23, 603-619. http://dx.doi.org/10.1521/jscp.23.5.603.50748

Parks, A. C., \& Biswas-Diener, R. (2013). Positive interventions: Past, present and future. In T. Kashdan \& J. Ciarrichi (Eds.), Bridging acceptance and commitment therapy and positive psychology: A practitioner's guide to a unifying framework. Oakland, CA: New Harbinger.

Pavot, W., \& Diener, E. (2008). The Satisfaction With Life Scale and the emerging construct of life satisfaction. Journal of Positive Psychology, 3, 137-152. http://dx.doi.org/10.1080/17439760701756946

Peterson, C., \& Seligman, M. E. P. (2004). Character strengths and virtues: A handbook and classification. Oxford, England: Oxford University Press. 
Praissman, S. (2008). Mindfulness-based stress reduction: A literature review and clinician's guide. Journal of the American Academy of Nurse Practitioners, 20, 212-216. http://dx.doi.org/10.1111/j.17457599.2008.00306.x

Rashid, T. (2008). Positive psychotherapy. In S. J. Lopez (Ed.), Positive psychology: Exploring the best in people, vol. 4 (pp. 187-217). Westport, CT: Praeger.

Ruch, W., Proyer, R. T., Harzer, C., Park, N., Peterson, C., \& Seligman, M. E. P. (2010). Values in action inventory of strengths (VIA-IS): Adaptation and validation of the German version and the development of a peer-rating form. Journal of Individual Differences, 31(3), 138-149. http://dx.doi.org/10.1027/1614-0001/a000022

Ryan, R. M., \& Deci, E. L. (2001). On happiness and human potentials: A review of research on hedonic and eudaimonic wellbeing. Annual Review of Psychology, 52, 141-166. http://dx.doi.org/10.1146/annurev.psych.52.1.141

Ryff, C. (1989). Happiness is everything, or is it? Explorations on the meaning of psychological wellbeing. Journal of Personality and Social Psychology, 57, 1069-1081. http://dx.doi.org/10.1037/0022$\underline{3514.57 .6 .1069}$

Segal, Z. V., Williams, M., \& Teasdale, J. (2002). Mindfulness-based cognitive therapy for depression: A new approach to preventing relapse. New York, NY: Guilford.

Seligman, M. E. P., Steen, T. A., Park, N. P., \& Peterson, C. (2005). Positive psychology progress: Empirical validation of interventions. American Psychologist, 60, 410-421. http://dx.doi.org/10.1037/0003-066X.60.5.410

Shapiro, D. H. (1982). Overview: Clinical and physiological comparisons of meditation with other selfcontrol strategies. American Journal of Psychiatry, 139, 267-274. http://dx.doi.org/10.1176/ajp.139.3.267

Shapiro, S. L., Oman, D., Thoresen, C. E., Plante, T. G., \& Flinders, T. (2008). Cultivating mindfulness: Effects on wellbeing. Journal of Clinical Psychology, 64, 840-862. http://dx.doi.org/10.1002/jclp.20491

Sin, N. L., \& Lyubomirsky, S. (2009). Enhancing wellbeing and alleviating depressive symptoms with positive psychology interventions: A practice-friendly meta-analysis. Journal of Clinical Psychology, 65, 467-487. http://dx.doi.org/10.1002/jclp.20593

Sugiura, Y. (2004). Detached mindfulness and worry: A meta-cognitive analysis. Personality and Individual Differences, 37(1), 169-179. http://dx.doi.org/10.1016/j.paid.2003.08.009

Wood, A. M., Linley, P. A., Matlby, J., Kashdan, T. B., \& Hurling, R. (2011). Using personal and psychological strengths leads to increases in wellbeing over time: A longitudinal study and the development of the strengths use questionnaire. Personality and Individual Differences, 50, 15-19. http://dx.doi.org/10.1016/j.paid.2010.08.004

Yardley, J. K., \& Rice, R. W. (1991). The relationship between mood and subjective wellbeing. Social Indicators Research, 24, 101-111. http://dx.doi.org/10.1007/BF00292653 